vol.4 No.2 - 2017

\title{
ASSESSMENT OF DIABETIC PATIENT'S KNOWLEDGE AND PRACTICE REGARDING DIABETIC FOOT ${ }^{1}$ Gazia Abdallah Abd-El Rohman, ${ }^{2}$ Hanan Mohamed Mohamed Soliman, ${ }^{3}$ Amany Mohammed Shebl \\ 1 B.S.c Nursing - Mansoura University \\ 2Assistant professor of Medical -Surgical Nursing Department, Faculty of Nursing, Mansoura University 3Professor of Medical-Surgical Nursing Department, Faculty of Nursing, Mansoura University
}

\begin{abstract}
Background: Diabetes Mellitus)DM) is a multi system disease affect many tissues and lead to many complications such as diabetic foot which result in foot ulcers and lower limb amputations that are considered major causes of morbidity, disability and mortality among patients with diabetes as well as emotional and physical costs. Aim of the study: Assessment of diabetic patient's Knowledge and Practice regarding Diabetic Foot. Design: The study design was a descriptive Correlation design. Setting: The study was conducted at the diabetic foot outpatient clinic in Specialized Medical Hospital at Mansura University. The study sample: A convenience sample of 196 adult diabetic patients with diabetic foot from both sex, age ranged +18-60 years old. Tools: Questionnaire interview sheet. Consisted of three parts: 1) Socio demographic characteristic and patient's medical data sheet, 2) Diabetic foot knowledge questionnaire, 3) Diabetic foot self reported practice questionnaire. Results: Results of this study showed that A highly significant relation between total patient's knowledge and their practice related to diabetic foot as the majority of the patients who had poor knowledge had poor practice $\mathrm{P}<0.001$. Conclusion: The patients with diabetes had poor knowledge and practice regarding diabetic foot care. Recommendation: Development of an educational program for patients with diabetes mellitus to improve patients' knowledge and their practices regarding diabetic foot car.
\end{abstract}

Key words: Diabetic patient, Diabetic Foot, knowledge, Practice

\section{Introduction:}

Diabetes Mellitus (DM) is a main public health problem and its complications especially hypertension and hyperlipidemia cause many severe health problems and is a leading cause of renal disease, vision loss and non-traumatic amputation (24). Egypt is one of the countries which significantly suffer from $\mathrm{DM}$, in which it is considered a main emerging clinical and public health difficult among the Egyptian population and it is a growing health problem all over the world, in 2012 there were number of people estimated to be 371 million having diabetes, with prevalence of $8.3 \%$ and this number is expected to increase to 552 million by 2030 worldwide. The
International Diabetes Federation reported that there were over 7.8 million cases of diabetes in Egypt in $2015^{(12)}$.

As this rises in prevalence of DM are possible to rise its complications among diabetic patients. One vital complications of DM is diabetic foot, this complication represent an important cause of hospitalization, non-traumatic amputation and death in patients with diabetes ${ }^{(5)}$.

Diabetic foot is a major health, economic, social and a leading cause of morbidity, disability and mortality especially in the developing countries, $15 \%$ of all patients with diabetes develop foot ulcers. More than $85 \%$ non traumatic 
amputations in diabetics patients occur in people who had an antecedent foot ulcer or infection ${ }^{(25)}$.

Diabetic foot ulcer is a main and severe complication of diabetes and is the most common cause of hospitalization related to diabetes and the major component of the diabetic foot. ${ }^{(7)}$.

The risk of diabetic foot increases in many diabetic patients because the patients not done daily foot care correctly, failing to perform a daily foot selfinspection, walking barefoot, wearing improper footwear or washing their feet with unsafe water and improperly trimming their toenails, (1). Some environmental factors like living in urban, poor hygienic conditions, poverty, barefoot gait, low income, and cultural practices. Diabetic patients are possible to develop foot ulcer, non-traumatic amputation if they do not have good knowledge and practice of foot care ${ }^{(5)}$.

\section{Significant of the Study}

The DM is a medical difficult with highly prevalence between different populations, and increase with age. Diabetes represent one of the major challenges for health care systems whole world and consuming a lot of health care resources because the disease can affect individual's health through involvement of several body systems with complications as serious as losing vision, amputation, renal failure, or Coronary Artery Disease $(\mathrm{CAD})^{(3)} .15 \%$ of all diabetic patients develop foot ulcers and more than $85 \%$ of lower limb amputation is due to diabetic foot ${ }^{(25)}$. Despite recent medical advance in treatment of DM, diabetic foot remain a major medical, social, economic and this may lead to morbidity and mortality in patient with diabetic foot, the cost of diabetic foot ulcers treatment is not only the cost of a dressing multiplied by the frequency of dressing change, it includes the nursing time, hospital stay, home health costs, and costs of complications ${ }^{(23)}$. So it is essential to conduct this study to assess diabetic patient's knowledge and practice regarding diabetic foot care, this help both the patients and health care providers to initiate measures and increase knowledge and practice of diabetic patients regarding diabetic foot care to prevent this problem.

\section{Operational Definitions: \\ Patients' Knowledge:}

Knowledge was classified according knowledge questionnaire into Good knowledge when the patients have a knowledge level more than 65\%, Average knowledge when the patients have a knowledge level 50-65\% and Poor knowledge when the patients have a knowledge level less than $50 \%$. Scores of all answers were summed up, the higher the score the higher knowledge level (Desalu et al,2011) $^{(5)}$.

\section{Patients' Practice:}

Based on self reported practice questionnaire practice was classified according to practice questionnaire into Good practice when the patients have a practice level more than $65 \%$, Average practice when the patients have a practice level 50-65\% and Poor practice when the patient have a practice level less than $50 \%$. Scores of all answers were summed up, higher score indicated better practice (Saleh, Shebl, Hatata \& Refiei, 2012) ${ }^{(20)}$.

\section{Aim of the study:}

1-Assess Patients' knowledge and practices regarding diabetic foot.

\section{Study questions:}

1- What are the patient's knowledge and practices regarding diabetic foot?

2- Is there a relationship between patients knowledge, practice and their socio demographic characteristics? 


\author{
Methods \\ Research Design: \\ A descriptive correlation research \\ design.
}

\section{Setting}

The study was conducted at the diabetic foot outpatient clinic in specialized medical hospital at Mansura University in delta region. The clinic started working from 9 AM to 1PM every day except Friday, clinic is closed. The clinic was well prepared for receiving patients with waiting places for those patients. There was a responsible nurse for calling each patient at frequent intervals to be checked by the doctor in the clinic.

\section{Sample:}

A Convenience sample of 196 adult patients (+18-60 years) diagnosed as DM with diabetic foot confirmed by diagnosis in the patient's file \& willing to participate in the study.

\section{Tools of Data Collection:}

Questionnaire interview sheet: This tool was developed by the researcher after extensive review of related \& recent literature and consist of three parts.

Part I- Socio demographic data sheet and patient's medical data sheet:

Socio demographic data such as age, sex, marital status, education level, occupation, nature of work and income.

\section{Medical data sheet:}

Past history: Type of diabetes, discovering diabetes, duration and felt symptoms of diabetes.

Family history: Suffering from diabetes, degree of relativity, history of diabetic foot, living with diabetic patient, affected and benefit from this.

$$
\text { Present history: diabetic }
$$

complication, hypoglycemic coma, hyperglycemic coma and other disease.
Part II: Diabetic foot knowledge questionnaire: used to assess patient's knowledge about diabetic foot.

This part included 29 items in total and divided into 6 categories. Meaning of diabetic foot, causes, signs \& symptoms, complications, prevention of diabetic foot, effect of diabetes on the foot.

Scoring system: It consisted of 29 items in total. Questions were in the form of multiple choice questions (MCQ), the total score are 29 marks graded as the following: One Point for a correct answer, Zero Point for an incorrect or I don't know answer.

The total patient's score were collected and evaluated as following:knowledge. knowledge.

- Less than $50 \%$ considered poor

- $50-65 \%$ considered average

- More than 65\% considered good knowledge (Desalu et al, 2011; Rocha et al, 2009) ${ }^{(5 \& 19)}$.

Part III: Diabetic foot self reported practice questionnaire: used to assess patient's self reported practice about diabetic foot.

This part included19 items in total and divided into 15 categories ${ }^{(5 \& 19)}$. Daily foot examination, Washing foot daily, Dryness between fingers after washing, Putting cream to moisture the feet, Elevating the feet from time to time, wearing socks, Changing socks daily, Keeping socks dry, Wearing shoes with smooth leisure, inspecting the shoes before wear, Walking barefoot in the home, Cutting nail by themselves, Intervention in case of wound injury.

Scoring system: All question in the form Yes and No and only one question in the form of multiple choice questions (MCQ) .A correct answer was scored 1; an incorrect answer was scored 0.Scores of each item were summed up, and the total score ranged from 0 to 19 . The total 
Gazia Abdallah Abd-El Rohman et. al.

\begin{tabular}{|c|c|}
\hline $\begin{array}{l}\text { patient's score were collected and } \\
\text { evaluated as following:- } \\
\text { - Less than } 50 \% \text { considered poor } \\
\text { practice. } \\
\text { - } 50-65 \% \text { considered average } \\
\text { practice. }\end{array}$ & $\begin{array}{l}\text { 8. Field of work: Tools were completed } \\
\text { through interviewing the patient } \\
\text { individualized and use patient medical } \\
\text { records. Patients were interviewed } \\
\text { during the morning in the diabetic foot } \\
\text { outpatient clinic. }\end{array}$ \\
\hline
\end{tabular}
practice $^{(5 \& 19)}$.

- More than $65 \%$ considered good

\section{Tool development:}

1. Tools were constructed and developed by the researchers after reviewing recent related literature.

2. Validity: the tools were tested for content related validity by seven experts (Jury) from Mansoura University. Six Professors in field and one professor in internal medicine in Mansoura University, they reviewed the tool for clearance and applicability for implementation. Modifications was done accordingly.

3. Reliability of the developed tool was estimated using the Cronbach's Alpha test to measure the internal consistency of the tools $r=0.815$

4. The researcher started data collection by introducing herself and explaining the purpose of the study.

5. The researcher collected data from 4 to 6 patients daily. Filling questionnaire required $20 \quad-30$ minutes. Data Collection Started from beginning of August 2014 to the end of November 2014.

6. The investigator coded the questionnaires to assure the anonymity of the subjects. Finally, the investigator scored the responses, and compiled them for data analysis.

7. Pilot Study: It was applied on $10 \%$ (20 patients) of total number of diabetic patients with Diabetic foot to test the simplicity, clarity of the questions and time frame needed for interview. This sample were excluded from the study. Minor modifications were done accordingly.

\section{Ethical Consideration and Patients' Rights:}

1. An official approval for conducting the study was obtained from the Ethical Committee of Faculty of Nursing of Mansoura University.

2. An official approval for conducting the study was obtained from the responsible administrative personnel of Faculty of Nursing of Mansoura University As well as permission from director of specialized medical hospital.

3. The researcher should obtain consent from patients to participate in this study after explaining the study aims. Patients were assured that the information is confidential and used for study purposes only.

4. Official permission to use patients' medical record.

5. The researcher emphasized that participation is absolutely voluntary and confidential.

6. Anonymity and privacy was assured during the study.

7. Honest was assured when dealing with patients and their data and findings.

\section{Statistical Analysis:}

The collected data were organized, categorized, tabulated and analyzed using the statistical package for social science "SPSS" the computer program "version 11.0". Data was presented in tables and charts using actual percentages. Test of significance was used. The tests used to summarize the data as mean and stander deviation test to compare mean scores for numerical data and chi square test to test the relationships. 


- The value of $<0.05$ was used as a
cut-off point for determination of
significance.
The value of $>0.05$ was used as acut-
off point for determination of non-
significance.

\section{Results:}

Table(1): Shows the distribution of study sample according to their sociodemographic data. Regarding age, less than two third of patients $(62.2 \%)$ were in the age ranged from 50-60years old. Concerning genders, more than half of patients were females (55.1\%).Regarding residence, more than half of patients $(51.5 \%)$ were living in the urban

.Regarding marital status, less than two third of patients $(63.8 \%)$ were married. The educational level, slightly more than one third of patients $(38.3 \%)$ were illiterate followed by $(30.1 \%)$ were moderate education. Regarding occupation status, more than half of patients $(58.2 \%)$ weren't working and in working group slightly more than one third of patients $(39.0 \%)$ were worked in governmental sector followed by $(25.6 \%)$ were farmers. Concerning monthly income, most of patients $(86.7 \%)$ have enough income. Regarding diabetic type, nearly the most of patients $(79.1 \%)$ were type II.

Table (2): Shows total knowledge level of diabetic patients about diabetic foot, most of patients $(90.3 \%)$ had poor total knowledge level about diabetic foot.

Table (3): Shows total diabetic patient's practices about diabetic foot, less than two third of patients $(62.8 \%)$ had poor total practices about diabetic foot.

Table (4): There is highly significant relation between total patients knowledge and total patient's practice related to diabetic foot as the majority of the patients who had poor knowledge had poor practice $\mathrm{P}=0.000$ *

Table (5):Shows the relationship between patient's knowledge related to diabetic foot and socio-demographic characteristics. It was noticed that there were statistically significance relation between patient's knowledge, residence, sex, education and job. Also, no statistically relation between patient's knowledge, age, marital status, income, body mass index and diabetic type.

Table (6): Shows relationship between patient's practices related to diabetic foot and Socio demographic data. There is statistically significance relation between patient's practices, residence, marital status, education, job and income. While there were no statistically significance relation between patient's practices, age, sex, body mass index and diabetic type. 
Gazia Abdallah Abd-El Rohman et. al.

\begin{tabular}{|c|c|c|}
\hline Item & $\mathrm{No}=196$ & )$\%($ \\
\hline $\begin{array}{l}\text { Age groups (in years): } \\
20->40 \mathrm{yrs} \\
40->50 \mathrm{yrs} \\
50-60 \mathrm{yrs}\end{array}$ & $\begin{array}{c}3 \\
71 \\
122 \\
\end{array}$ & $\begin{array}{r}1.5 \\
36.2 \\
62.3 \\
\end{array}$ \\
\hline $\begin{array}{l}\text { Gender: } \\
\text { Male } \\
\text { Female }\end{array}$ & $\begin{array}{c}88 \\
108\end{array}$ & $\begin{array}{r}44.9 \\
55.1\end{array}$ \\
\hline $\begin{array}{l}\text { Residence: } \\
\text { Rural } \\
\text { Urban }\end{array}$ & $\begin{array}{c}95 \\
101\end{array}$ & $\begin{array}{l}48.5 \\
51.5\end{array}$ \\
\hline $\begin{array}{l}\text { Marital status: } \\
\text { Single } \\
\text { Married } \\
\text { Divorced } \\
\text { Widowed }\end{array}$ & $\begin{array}{c}4 \\
125 \\
21 \\
46\end{array}$ & $\begin{array}{l}2.0 \\
63.8 \\
10.7 \\
23.5\end{array}$ \\
\hline $\begin{array}{l}\text { Level of education: } \\
\text { Illiterate } \\
\text { read and write } \\
\text { moderate } \\
\text { academic }\end{array}$ & $\begin{array}{l}75 \\
38 \\
59 \\
24\end{array}$ & $\begin{array}{l}38.3 \\
19.4 \\
30.1 \\
12.2\end{array}$ \\
\hline $\begin{array}{l}\text { Employment: } \\
\text { Working } \\
\text { Not working }\end{array}$ & $\begin{array}{c}82 \\
114\end{array}$ & $\begin{array}{l}41.8 \\
58.2\end{array}$ \\
\hline $\begin{array}{l}\text { Occupation: } \\
\text { Governmental sectors } \\
\text { Private sector } \\
\text { Worker } \\
\text { Farmer }\end{array}$ & $\begin{array}{c}32 \\
20 \\
9 \\
21\end{array}$ & $\begin{array}{l}39.0 \\
24.4 \\
11.0 \\
25.6\end{array}$ \\
\hline $\begin{array}{l}\text { Monthly Income } \\
\text { Enough - More than } 1500 \\
\text { Not enough - Less than } 1500\end{array}$ & $\begin{array}{c}170 \\
26\end{array}$ & $\begin{array}{l}86.7 \\
13.3\end{array}$ \\
\hline
\end{tabular}

Table (2): Total knowledge level of diabetic patients about diabetic foot in study sample $(\mathrm{N}=196)$.

\begin{tabular}{|c|c|c|c|}
\hline Total patient's knowledge & No =196 & (\%) & Mean \pm SD \\
\cline { 1 - 3 } Poor & 177 & 90.3 & \multirow{2}{*}{$9.55 \pm 4.77$} \\
\cline { 1 - 3 } Average & 19 & 9.7 & \\
\hline
\end{tabular}

Table (3): Total diabetic patient's practices related to diabetic foot $(\mathrm{N}=196)$.

\begin{tabular}{|c|c|c|c|}
\hline Total patient's practices & No $=\mathbf{1 9 6}$ & $\mathbf{( \% )}$ & \multirow{2}{*}{ Mean \pm SD } \\
\hline Poor & 123 & 62.8 & \multirow{2}{*}{$6.11 \pm 2.57$} \\
\hline Average & 35 & 17.9 & \\
\hline Good & 38 & 19.3 & \\
\hline
\end{tabular}


ASSESSMENT OF DIABETIC PATIENT'S KNOWLEDGE AND etc...

Table (4): Relationship between total patients knowledge score and total patient's practice score related to diabetic foot $(\mathrm{N}=196)$.

\begin{tabular}{|c|c|c|c|c|c|c|}
\hline \multirow{3}{*}{$\begin{array}{c}\text { Total practice } \\
\text { score }\end{array}$} & \multicolumn{4}{|c|}{ Total Knowledge score } & \multirow{3}{*}{$\mathrm{x}^{2}$} & \multirow{3}{*}{ P-Value } \\
\hline & \multicolumn{2}{|c|}{ Poor $<50 \%$} & \multicolumn{2}{|c|}{ Average 50-65 } & & \\
\hline & No & $\%$ & No & $\%$ & & \\
\hline Poor & 120 & 67.8 & 3 & 15.8 & \multirow{3}{*}{28.306} & \multirow{3}{*}{$.000 * *$} \\
\hline Average & 31 & 17.5 & 4 & 21.1 & & \\
\hline Good & 26 & 14.7 & 12 & 63.2 & & \\
\hline Total & 177 & 90.3 & 19 & 9.7 & & \\
\hline
\end{tabular}

Table (5): Relationship between patient's knowledge related to diabetic foot and sociodemographic characteristics ( $\mathrm{N}=196)$.

\begin{tabular}{|c|c|c|c|c|c|c|}
\hline \multirow{3}{*}{ Item } & \multicolumn{4}{|c|}{ Patient's knowledge } & \multirow{3}{*}{$\mathbf{x}^{2}$} & \multirow{3}{*}{$\begin{array}{c}\text { P- } \\
\text { Value }\end{array}$} \\
\hline & \multicolumn{2}{|c|}{$\begin{array}{c}\text { Poor }<50 \% \\
\text { No }=177\end{array}$} & \multicolumn{2}{|c|}{$\begin{array}{c}\text { Average 50-65\% } \\
\text { No }=19\end{array}$} & & \\
\hline & No & $\%$ & No & $\%$ & & \\
\hline $\begin{array}{c}\text { Age: } \\
\quad<40 \mathrm{yrs} \\
40-50 \mathrm{yrs} \\
>50 \mathrm{yrs}\end{array}$ & $\begin{array}{c}3 \\
65 \\
109\end{array}$ & $\begin{array}{c}1.7 \\
36.7 \\
61.6\end{array}$ & $\begin{array}{c}0 \\
6 \\
13\end{array}$ & $\begin{array}{c}0 \\
31.6 \\
68.4\end{array}$ & . 0576 & .750 \\
\hline $\begin{array}{r}\text { Residence: } \\
\text { Rural } \\
\text { Urban }\end{array}$ & $\begin{array}{l}90 \\
87\end{array}$ & $\begin{array}{l}50.8 \\
49.2\end{array}$ & $\begin{array}{c}5 \\
14\end{array}$ & $\begin{array}{l}26.3 \\
73.7\end{array}$ & 4.134 & $.042 *$ \\
\hline $\begin{array}{r}\text { Gender: } \\
\text { Male } \\
\text { Female }\end{array}$ & $\begin{array}{c}75 \\
102\end{array}$ & $\begin{array}{l}42.4 \\
57.6\end{array}$ & $\begin{array}{c}13 \\
6\end{array}$ & $\begin{array}{l}68.4 \\
31.6\end{array}$ & 4.706 & $.030 *$ \\
\hline $\begin{array}{c}\text { Marital status: } \\
\text { Single } \\
\text { Married } \\
\text { Divorced } \\
\text { Widow }\end{array}$ & $\begin{array}{c}3 \\
112 \\
20 \\
42 \\
\end{array}$ & $\begin{array}{c}1.7 \\
63.3 \\
11.3 \\
23.7 \\
\end{array}$ & $\begin{array}{c}1 \\
13 \\
1 \\
4 \\
\end{array}$ & $\begin{array}{c}5.3 \\
68.4 \\
5.3 \\
21.1 \\
\end{array}$ & 1.778 & .620 \\
\hline $\begin{array}{c}\text { Education: } \\
\text { Illiterate } \\
\text { Read\& write } \\
\text { Moderate } \\
\text { Academic }\end{array}$ & $\begin{array}{l}74 \\
37 \\
52 \\
14 \\
\end{array}$ & $\begin{array}{c}41.8 \\
20.9 \\
29.4 \\
7.9 \\
\end{array}$ & $\begin{array}{c}1 \\
1 \\
7 \\
10 \\
\end{array}$ & $\begin{array}{c}5.3 \\
5.3 \\
36.8 \\
52.6 \\
\end{array}$ & 36.497 & $.000 *$ \\
\hline $\begin{array}{l}\text { Job: } \\
\text { Working } \\
\text { Not working }\end{array}$ & $\begin{array}{c}66 \\
111\end{array}$ & $\begin{array}{l}37.3 \\
62.7\end{array}$ & $\begin{array}{c}16 \\
3\end{array}$ & $\begin{array}{l}84.2 \\
15.8\end{array}$ & 15.525 & $.000 *$ \\
\hline $\begin{array}{c}\text { Income: } \\
\text { Enough } \\
\text { Not enough }\end{array}$ & $\begin{array}{c}151 \\
26\end{array}$ & $\begin{array}{l}85.3 \\
14.7\end{array}$ & $\begin{array}{c}19 \\
0\end{array}$ & $\begin{array}{c}100.0 \\
0.0\end{array}$ & 3.218 & .058 \\
\hline
\end{tabular}


Gazia Abdallah Abd-El Rohman et. al.

Table (6): Relationship between patients practices related to diabetic foot and Sociodemographic characteristics $(\mathrm{N}=196)$.

\begin{tabular}{|c|c|c|c|c|c|c|c|c|}
\hline \multirow{3}{*}{ Item } & \multicolumn{6}{|c|}{ patient's practice } & \multirow{3}{*}{$\mathbf{X}^{2}$} & \multirow{3}{*}{$\begin{array}{c}\text { P- } \\
\text { Value }\end{array}$} \\
\hline & \multicolumn{2}{|c|}{$\begin{array}{c}\text { Poor }<50 \% \\
\text { No }=123\end{array}$} & \multicolumn{2}{|c|}{$\begin{array}{l}\text { Average } \\
\mathbf{5 0 - 6 5 \%} \\
\text { No }=35\end{array}$} & \multicolumn{2}{|c|}{$\begin{array}{c}\text { Good }>65 \% \\
\text { No }=38\end{array}$} & & \\
\hline & No & $\%$ & No & $\%$ & No & $\%$ & & \\
\hline Age: & & & & & & & & \\
\hline$<40 \mathrm{yrs}$ & 2 & 1.6 & 0 & 0 & 1 & 2.6 & 4.901 & .298 \\
\hline $40-50 y r s$ & 38 & 30.9 & 16 & 45.7 & 17 & 44.7 & & \\
\hline$>50 \mathrm{yrs}$ & 83 & 67.5 & 19 & 54.3 & 20 & 52.6 & & \\
\hline Residence: & & & & & & & & \\
\hline rural & 69 & 56.1 & 14 & 40.0 & 12 & 31.6 & 8.211 & $.016 *$ \\
\hline Urban & 54 & 43.9 & 21 & 60.0 & 26 & 68.4 & & \\
\hline Gender: & & & & & & & & \\
\hline male & 53 & 43.1 & 15 & 42.9 & 20 & 52.6 & 1.140 & .565 \\
\hline Female & 70 & 56.9 & 20 & 57.1 & 18 & 47.4 & & \\
\hline Marital status: & & & & & & & & \\
\hline single & 4 & 3.3 & 0 & .0 & 0 & .0 & & \\
\hline married & 74 & 60.2 & 19 & 54.3 & 32 & 84.2 & 12.963 & $.044 *$ \\
\hline divorced & 12 & 9.8 & 7 & 20.0 & 2 & 5.3 & & \\
\hline widow & 33 & 26.8 & 9 & 25.7 & 4 & 10.5 & & \\
\hline Education: & & & & & & & & \\
\hline illiterate & 69 & 56.1 & 5 & 14.3 & 1 & 2.6 & & \\
\hline read\& write & 27 & 22.0 & 8 & 22.9 & 3 & 7.9 & 91.957 & $.000 * *$ \\
\hline moderate & 25 & 20.3 & 18 & 51.4 & 16 & 42.1 & & \\
\hline academic & 2 & 1.6 & 4 & 11.4 & 18 & 47.4 & & \\
\hline Job: & & & & & & & & \\
\hline working & 39 & 31.7 & 14 & 40.0 & 29 & 76.3 & 23.800 & $.000 * *$ \\
\hline not working & 84 & 68.3 & 21 & 60.0 & 9 & 23.7 & & \\
\hline Income: & & & & & & & & \\
\hline enough & 99 & 80.5 & 34 & 97.1 & 37 & 97.4 & 11.202 & $.004 *$ \\
\hline not enough & 24 & 19.5 & 1 & 2.9 & 1 & 2.6 & & \\
\hline
\end{tabular}

\section{Discussion:}

The discussion will be presented in the following sequence:

1- Socio demographic characteristics

2- Patient's knowledge regarding diabetic foot.

3- Patient's practice regarding diabetic foot.

4- Relationship between patient's knowledge related to diabetic foot and socio-demographic characteristics.
5- Relationship between patient's practices related to diabetic foot and Socio-demographic characteristics.

Regarding socio demographic characteristics: Regard patients' age, the finding of this study represents that less than two third of patients aged ranged from 50-60 years old. This result is in agreement with Al-Asmary,Mostafa and Al -Khaldi $(2013)^{(2)}$; Gholap and Mohite (2013) (10); Luttfi, Zaraihah and Ramadhan (2014) ${ }^{(16)}$ they found more 
ASSESSMENT OF DIABETIC PATIENT'S KNOWLEDGE AND etc...

than half of study subject aged ranged from 50-60 years old. This result could be attributed to increase age associated with many problems as peripheral disease, diabetic neuropathy and chronic venous insufficiency.

Concerning gender, more than half of subjects were females, this result comes in agreement with Ez -Eldeen, Fathey , Hassaballah and Basal $(2012)^{(9)}$; Saleh , Shebl, Hatata and Refiei (2012) ${ }^{(20)}$ they found that the higher incidence was among females. This result might be due to most of patients were not working, staying at home, obese, illiterate, busy with other things as housewife, caring with other family member and not having health awareness so they were not caring with their feet.

Regarding residence, more than half of patients were live in the urban, this result supported by with Seid and Tsige (2015) $^{(22)}$ who found more than half of patients were live in the urban. This result could be attributed to increase awareness about diabetic foot clinic in urban than rural in addition to the clinic is far from the rural area.

Regarding marital status, less than two third of patients were married, this result is consistent with Ali (2013) ${ }^{(3)}$; Al Asmary ,Mostafa and Al -Khaldi $(2013)^{(2)}$; Salmani and Hosseini (2010) (21)they mentioned that the majority of patients were married .

Concerning educational level ,slightly more than one third of patients were illiterate, this result come in accordance with Mohamed, Elsaher , Aref and Fouad (2015) ${ }^{(17)}$ who reported the same result.

Regarding employment, more than half of patients were not working this result is agreement with Elshenawe, Shalan and Abdelaziz (2013) ${ }^{(8)}$ who reported that the majority of patient is house wife, this could be attributed to most of patients in study were female and illiterate and the female with increase age and deterioration of their health, the female prefer to stay in home.

Concerning monthly income, most of patients had enough income, these result is agree with El - Khawaga and Abdel - Wahab (2015) ${ }^{(6)}$ who reported that the majority of patients had enough income.

Regarding total patient's knowledge about diabetic foot, the finding of this study showed the most of patients had poor knowledge level about diabetic foot. This result is agreement with Khamseh, Vatankhah and Baradaran (2007) ${ }^{(14)}$; Luttfi,Zaraihah and Ramadhan (2014) ${ }^{(16)}$ they reported that the majority of patients had poor knowledge about diabetic foot.

Regarding total patient's practice about diabetic foot: The finding of this study showed that less than two third of patients had poor total practices about diabetic foot. This study agreement with Desalu et al., (2011) ${ }^{(5)}$; Khamseh, Vatankhah and Baradaran (2007) ${ }^{(14)}$; Luttfi,Zaraihah and Ramadhan (2014) $^{(16)}$ they demonstrated the same result. This result could be attributed to the most of patient had poor total knowledge about diabetic foot this lead to poor total practice about diabetic foot.

Regarding the relationship between total knowledge score and total practice score related to diabetic foot, the present study revealed there is highly statistically significance relation between total knowledge score and total practice score related to diabetic foot which means that the higher the knowledge score the higher the practice total practice score. This result is consistence with Desalu et al., (2011) ${ }^{(5)}$; Gholap and Mohite (2013) (10); Jeewantha and Madushan (2011) ${ }^{(13)}$ they reportedthe same result.

Regarding relationship between patient's knowledge related to diabetic foot 
and socio-demographic characteristic, this study revealed statistically significance relation between patient's knowledge about diabetic foot and residence, as it was shown increase knowledge level with patients live in urban than patient live in rural, this result might be due to increase awareness in urban than rural. These result is consistence with El - Khawaga and Abdel - Wahab (2015) ${ }^{(6)}$ who found the same result.

Also the finding showed that there were statistically significance relation between patient's knowledge about diabetic foot and their gender. The knowledge level about diabetic foot is increase in male than female, these result is agree with Saleh,Shebl, Hatata and Refiei (2012) ${ }^{(20)}$ who reported the same result. This finding might be due to males are more better educated and going outdoor the home than females which may expose them extra to information than females.

Another marked finding in this study is that there was statistically significance relation between patient's knowledge about diabetic foot and education level. The knowledge level about diabetic foot is increase in academic patients than other level of education, this finding might be due to academic educated patient is able to read more about the disease. These result in the same line with Hasnain and Sheikh (2009) ${ }^{(11)}$; Saleh ,Shebl, Hatata and Refiei (2012) ${ }^{(20)}$ they reported the same result.

The present study represent statistically significance relation between patient's knowledge about diabetic foot and employment, the patients were working had average knowledge score than not working patients, these result is agreement with Al-Asmary, Mostafa and Al -Khaldi $(2013)^{(2)}$; Gholap and Mohite (2013) ${ }^{(10)}$ they found the same finding. The working patients had average knowledge than not working, these result might be due to work and social contact with other people increase knowledge level.

Also the present study represent no significant relation between patient's knowledge about diabetic foot and their age , as the patient age ranged from 50-60 had poor knowledge than other age group, this result might be due to the process of aging and weakness of memory. These result is agree with Luttfi,Zaraihah and Ramdhan (2014) (16); Saleh,Shebl, Hatata and Refiei (2012) $)^{(20) .}$

One of the marked findings in this study that there were no statistically significance relation between patient's knowledge about diabetic foot and marital status, these result is not agreement with Gholap and Mohite (2013) ${ }^{(10)}$; Saleh

,Shebl, Hatata and Refiei (2012) ${ }^{(20)}$; Seid and Tsige (2015) ${ }^{(22)}$ they found there was statistically significance relation between patient's knowledge about diabetic foot and marital status .The knowledge level is rise in married than divorced, single, as married patients encourage and assistance each other to increase their knowledge about the disease.

The present study revealed no statistically significance relation between knowledge of diabetic patients about diabetic foot and income, these result is agreement with Hasnain and Sheikh (2009) $^{(11)}$; Luttfi , Zaraihah and Ramdhan (2014) $)^{(16)}$ they reported the same result ,but these result is not agree with Saleh ,Shebl, Hatata and Refiei $(2012)^{(20)}$ who reported statistically significance relation between knowledge of patients about diabetic foot and income

This study represent no significant relation between knowledge about diabetic foot and diabetic type, these result is agree with Al-Asmary, Mostafa and Al -Khaldi (2013) ${ }^{(2)}$ who found the same result. 
Relationship between patient's practices about diabetic foot and socio demographic data, the present study represent significant statistical relation between patient's practices about diabetic foot and residence. The patients in urban had good practice level than patients in rural this result might be due to increase awareness in urban, these result is agreement with Gholap and Mohite (2013) (10) who found that there was a significance relation between practices of diabetic patients about diabetic foot and residence

An interesting finding in this study is that there was significance relation between patient's practices about diabetic foot and marital status ,the married patients had good level of practice about diabetic foot than widow and divorced because married patients remember, support and encourage each other to perform self care activities to avoid any complication as diabetic foot ,these result is agreement with Gholap and Mohite (2013) $^{(10)}$; Seid and Tsige (2015) ${ }^{(22)}$ they found the same finding.

The present study revealed statistically significance relation between patient's practices about diabetic foot and education, this result in same line with $\mathbf{A l}$

-Asmary , Mostafa and Al -Khaldi $(2013)^{(2)}$; Salmani and Hosseini (2010) $^{(21)}$ they reported that significant relation between patient's practices about diabetic foot and education, it means that diabetic patients with higher education had good practice about foot care than illiterate, this finding might be due to educated patient is able to search on update self care practice to avoid any complication.

One of the marked findings in the present study that there was significant relation between patient's practices about diabetic foot and employment. The patients were working had good practice than patients were not working, these result is agreement with Gholap M. C. and Mohite (2013) ${ }^{(10)}$ who found the same result . This finding might be due to the working patients had good practice about diabetic foot due to social contact.

The present study represent significant statistical relation between patient's practices about diabetic foot and income, these result is agree with Desalu et al., $(\mathbf{2 0 1 1})^{(5)}$ they reported that significant statistical relation between patient's practices about diabetic foot and income, but these result is not consistence with Luttfi , Zaraihah and Ramdhan (2014) $^{(16)}$ who demonstrated that no statistically significance relation between patient's practices about diabetic foot and income.

Also the present study revealed no statistically significance relation between patient's practices about diabetic foot and their age , as the patients age ranged from 50-60 had poor practice than other age group, this result might be due to older patients are not able to perform daily foot care practice because of aging. These result is agree with Luttfi , Zaraihah and Ramdhan (2014) ${ }^{(16)}$ who reported that no significant statistical difference between patient's practices about diabetic foot and their age, but these result is not agree with Al -Asmary , Mostafa and Al -Khaldi $(\mathbf{2 0 1 3})^{(2)}$ who found statistically significance relation between patient's practices about diabetic foot and their age.

Another marked finding in this study, there was no significant relation between patient's practices about diabetic foot and gender, As the male had good practice level than female, this finding may be due to males are more educated and going outdoor the home than females which may expose them more to knowledge and experience than women. These result is agree with Luttfi, Zaraihah and Ramdhan (2014) ${ }^{(16)}$ who reported the same finding. 
The present study represent no statistically significnce relation between patient's practices about diabetic foot and diabetic type. The patients in type II had good practice than patients with type I, these result is consistence with Al Asmary, Mostafa and Al -Khaldi $\mathbf{( 2 0 1 3 )}^{(2)}$ who found the similar finding.

\section{Conclusion:}

The present study concluded that: The majority of patients with diabetes had poor knowledge and practice regarding diabetic foot, There is statistically significance relation between patient's knowledge and practice related to diabetic foot .

\section{Recommendation:}

Based on the findings of the study the following recommendations are suggested: 1) An educational program should be developed for patients with diabetes mellitus to improve patients' knowledge and their practices regarding treatment regimen of diabetes to prevent diabetic complications especially diabetic foot.2) Implementing program for all diabetic patients in hospital about foot care to provide them with required necessary knowledge and skills about foot care.3)Constant health education by brochures and booklet to enhance patient's knowledge and practice regarding diabetic foot. 4) Further research; is recommended to provide a standard guidelines for nurses in order to enhance their practice in diabetic foot outpatient clinic and improve patients' knowledge and their practice. 5)Replication of the study in different geographical areas.

\section{References}

1. Abd El- Rahman S. K. and Abo shousha A. (2015) Effect of an Educational Program on Caregivers, Knowledge about Diabetic Foot Care at Elderly Home in Damanhur -
Egypt. Journal of American Science; 11(1):99- 100.

2. Al-Asmary A. S., Mostafa O. A. and Al - Khaldi Y. M. ( 2013 ) .Diabetic Patient's Knowledge and Practice regarding Prevention of Diabetic Foot. Medical Journal of Cairo University;8192): 197 - 205.

3. Ali H. S. (2013) Effectiveness of the use of cutimedsorbact versus standard dressing by nurses in diabetic foot ulcer. Life Science Journal;10 (2):1083- 1091.

4. Chaudhary S. and Chaudhary F. (2010). Awareness about Diabetes Risk Factors \& Complications in Diabetic Patients: A Cross-Sectional Study. Nishtar Medical Journal; 2(3)(available at www.google.com)

5. Desalu O. O., Salaw F. K., Jimoh A. K. , Adekoya A. O. , Busario O. A. andOlokoba A. B. ( 2011) Diabetic Foot Care :Self Reported Knowledge and Practice Among patients Attending Tree Tertiary Hospital in Nigeria .Ghana Medical Journal ;45(2) : 6065.

6. El - Khawaga G. and Abdel - Wahab F. (2015) .Knowledge , Attitude , Practice and Compliance of Diabetic patients in Dakahlia, Egypt

.European Journal of research in medical sciences ;3(1):40 - 53 .

7. El - Sayed D.M. (2012): Assessment of Nurses Performance Caring for Patients with Diabetic foot. Unpublished Master's thesis, In Nursing Science, Faculty of Nursing, Benha University, Egypt.

8. Elshenawe H.A., Shalan W. E. A. and Abdelaziz A.E. (2013) Effect of Ozone Olive Ointment Dressing Technique on the Healing of Superficial and Deep Diabetic Foot Ulcer. Journal of American Science; 9 (11): $235-250$.

9. Ez -Eldeen M. E., Fathey R., Hassaballah. A.E. and Basal A. A. 
(2012).Topical Honey Versus . Malaysian medical orthopedic Alginate as Dressing for Management of Wagner Type 2 Diabetic Ulcer. Journal of American Science; 8(9): $459-464$.

10. Gholap M. C. and Mohite V. R. (2013). To Assess the Knowledge and Practice Regarding Foot Care Among Diabetes Patients at Krighna Hospital. Journal Science Research; (4) 2: $69-75$.

11. Hasnain S. and Sheikh N. H. (2009) Knowledge and practices regarding foot care in diabetic patients visiting diabetic clinic in Jinnah Hospital, Lahore .Medical Association Journal ; 59(10) : $687-690$.

12. International Diabetes Federation (IDF) (2015): global estimates of the prevalence of diabetes for 2015 and 2030. Diabetes Res Clin Pract.; 94(3): 311-21. Available at http// www.idf.org > IDF general assessed at $13,8,2016$

13. Jeewantha M. and Madushan C. V. M. (2011) .A study to determine the knowledge and practices of foot care in patients with chronic diabetic ulcers. International Journal of Collaborative Research on Internal Medicine \& Public Health;3(1): 115 122.

14. Khamseh M.E., Vatankhah N. and Baradaran H.R.(2007).Knowledge and Practice of Foot Care in Iranian People with Diabetes. International Wound Journal; 4(4):298 - 302.

15. Lee, J.M., Gebremariam, A., Vijan, S., et al. (2012): Excess body mass index-years, a measure of degree and duration of excess weight, and risk for incident diabetes. Arch Pediatr Adolesc Med; 166(1):42-8.

16. Luttfi A. R.,Zaraihah M. R. and Ramadhan I. M. (2014).Knowledge and Practice of diabetic foot care in an in- patient setting at tertiary center

Journal; 8 (3):22 - 26.

17. Mohamed H.A., Elsaher H.E., Aref M.S. and Fouad N.(2015). The Effect of Diabetic Foot Training Program on Elderly Adults Outcome .Journal Of Nursing and Health Science; 4(4):14 -20.

18. Ochoa A. E.,Caliri K. and Fernandes(2006).knowledge on diabetes mellitus in self care process .Journal of American science ;7 (10):728 734.

19. Rocha R. M. ,Zanetti M. L. and Snatos M. A. (2009) . Behavior and Knowledge :Basis for prevention of diabetic foot .Act Paul Enferm ;22(1) $: 17-23$.

20. Saleh N. M. ,Shebl A. M. Hatata E. Z. and Refiei M.R. (2012).Impact of Educational Program about foot care on knowledge and self care practice for Diabetic Older Adult Patients .Journal of American Science;8(12): 1444 - 1452.

21. Salmani N. and Hosseini S. V. (2010). Foot Self Care in Diabetic Patients. IRANIAN Journal of Diabetes and Obesity;2(2):37 - 39.

22. Seid A. and Tsige Y. (2015). Knowledge ,Practice and Barriers of Foot Care among Diabetic Patients Attending FelegeHiwotRefferal Hospital , Bahir Dar , North West Ethiopia Diabetic Nursing Journal ;52(10):209 - 230.

23. White R. and Mcintosh C. (2008) Topical therapies for diabetic foot ulcers. Journal of Wound Care;10(17):426- 430.

24. Young J.(2011):Educating staff nurses on diabetes: Knowledge enhancement MEDSURG Nursing; 20(3):143- 150.

25. Zubair M., Malik A. and Ahmed J. (2011) Diabetic foot ulcer. American Journal of Internal Medicine; 3(2): 28-49. 